\title{
S3 File. The NMR spectra of M3.
}

Fig. S3-1 ${ }^{1} \mathrm{H}$ NMR spectrum of M3 (500 MHz, DMSO, $\left.25^{\circ} \mathrm{C}\right)$.

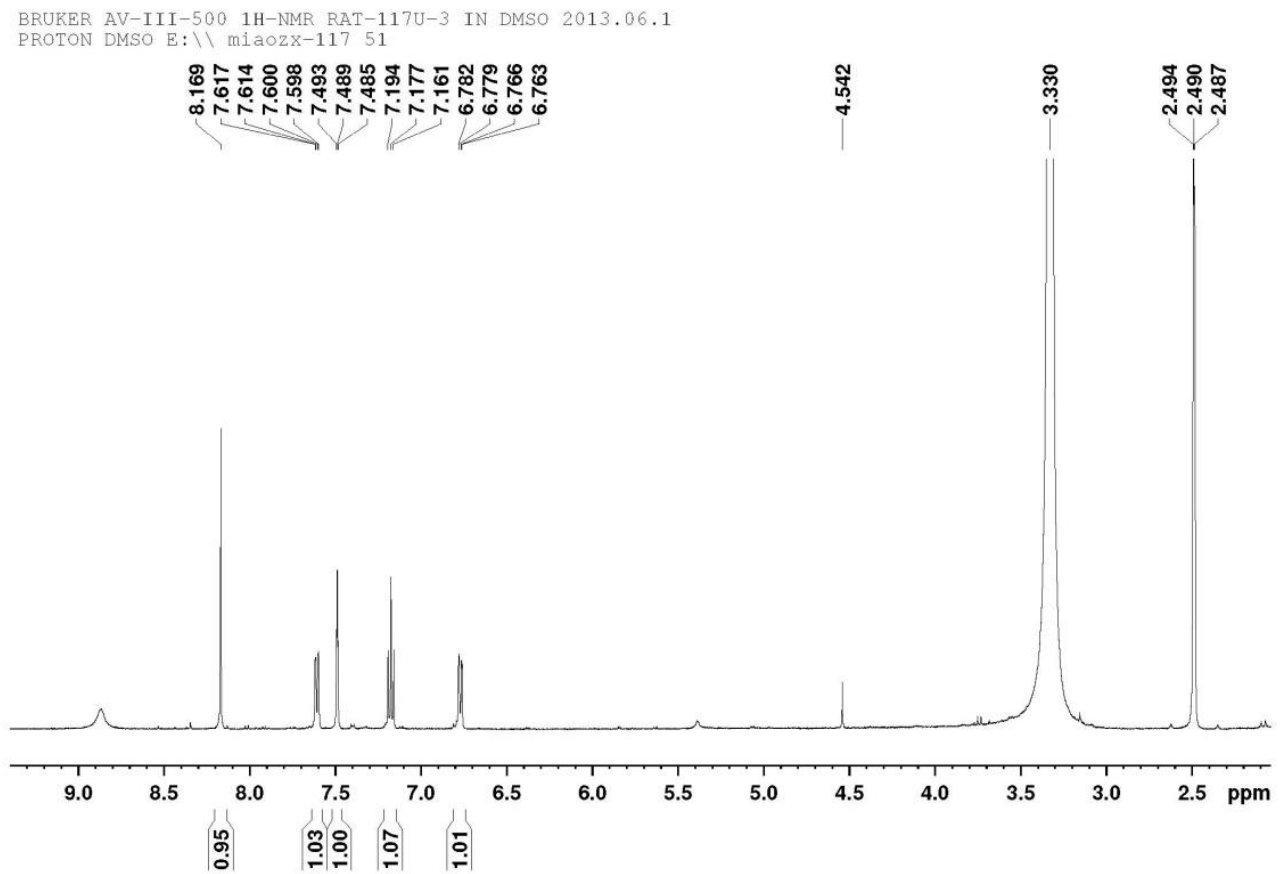

Fig. S3-2 ${ }^{1} \mathrm{H}$ NMR spectrum of M3 (500 MHz, DMSO, $\left.25^{\circ} \mathrm{C}\right)$.

BRUKER AV-III-500 1H-NMR RAT-117U-3 IN DMSO 2013.06.1

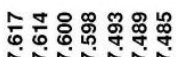

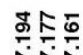

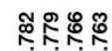

$\stackrel{\infty}{\infty}$

पit?

1if

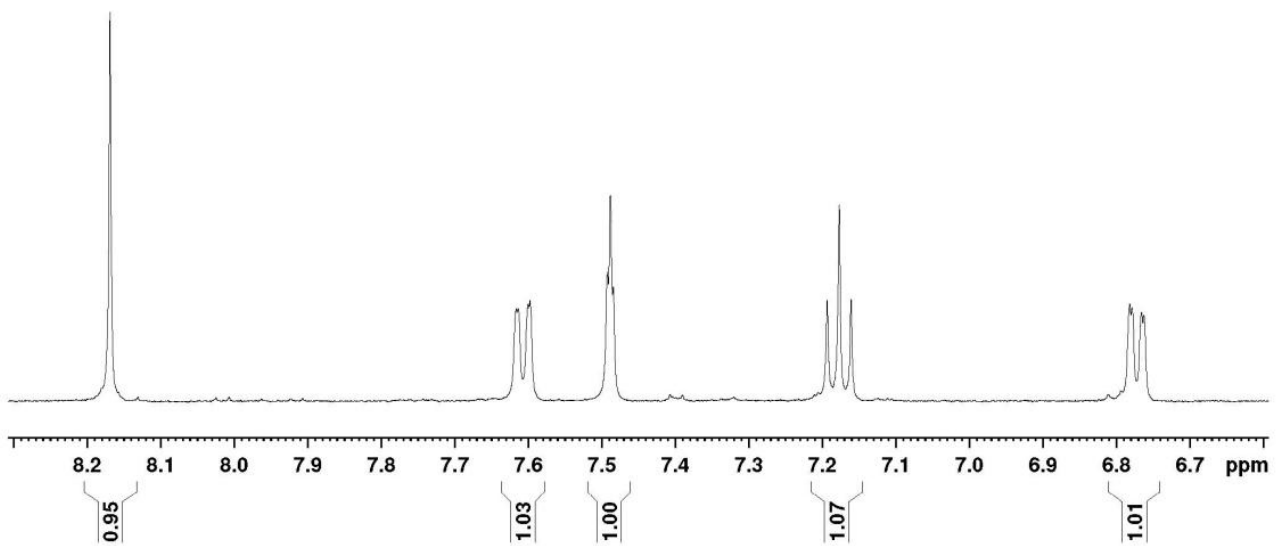


Fig. S3-3 COSY NMR spectrum of M3 (500 MHz, DMSO, $\left.25^{\circ} \mathrm{C}\right)$.

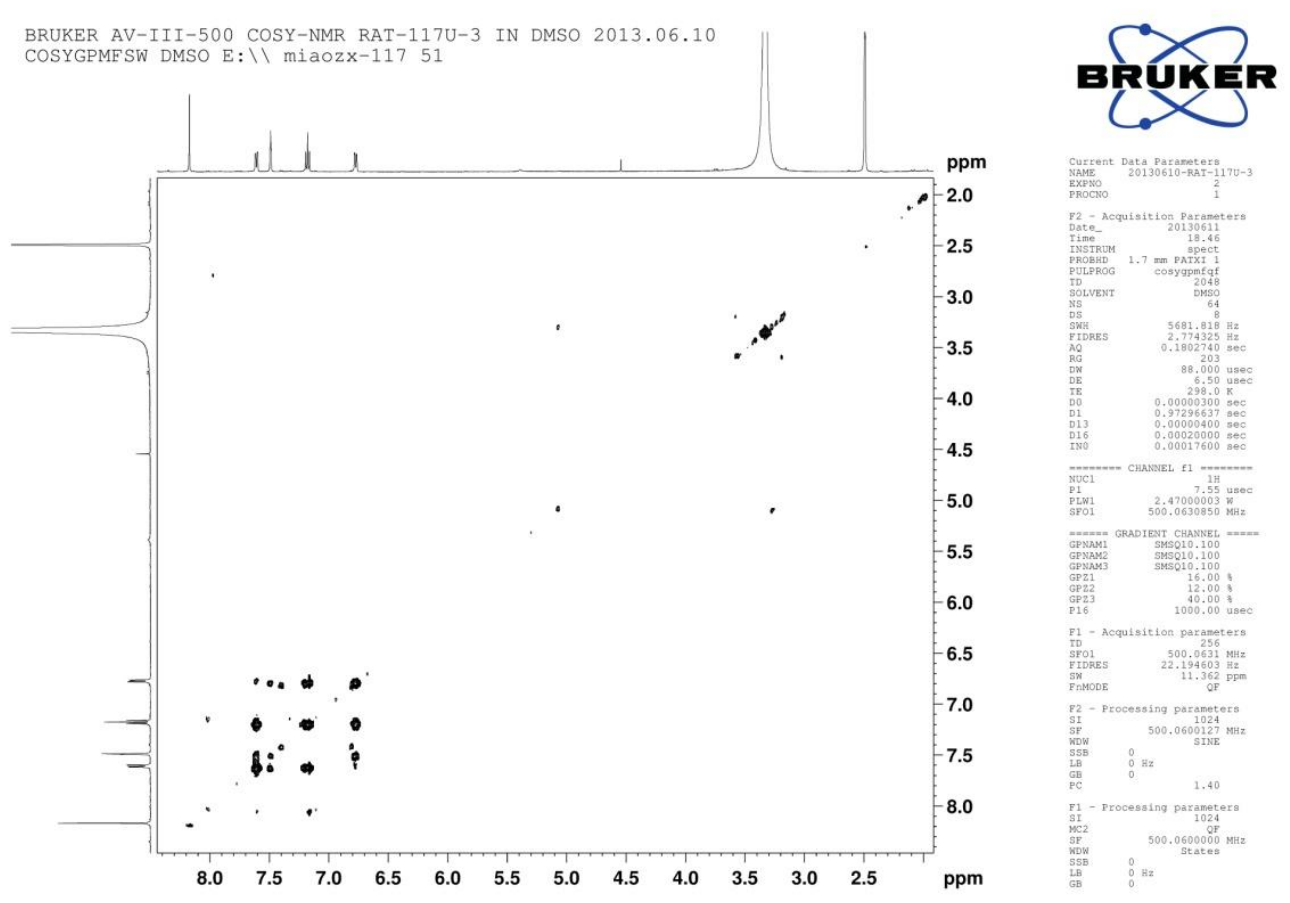

Fig. S3-4 COSY NMR spectrum of M3 (500 MHz, DMSO, 25 ${ }^{\circ} \mathrm{C}$ ).

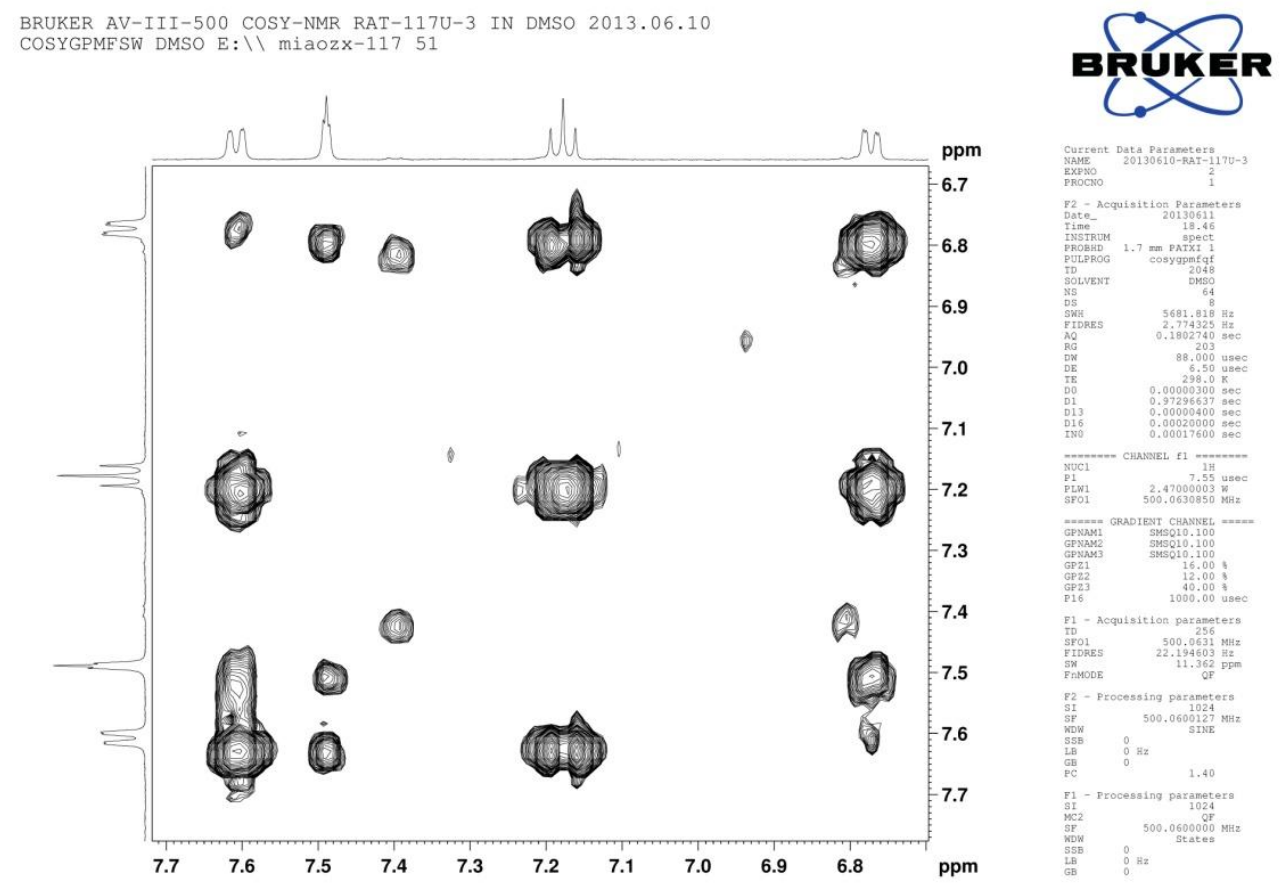


Fig. S3-5 HSQC NMR spectrum of M3 (500 MHz, DMSO, $\left.25^{\circ} \mathrm{C}\right)$.

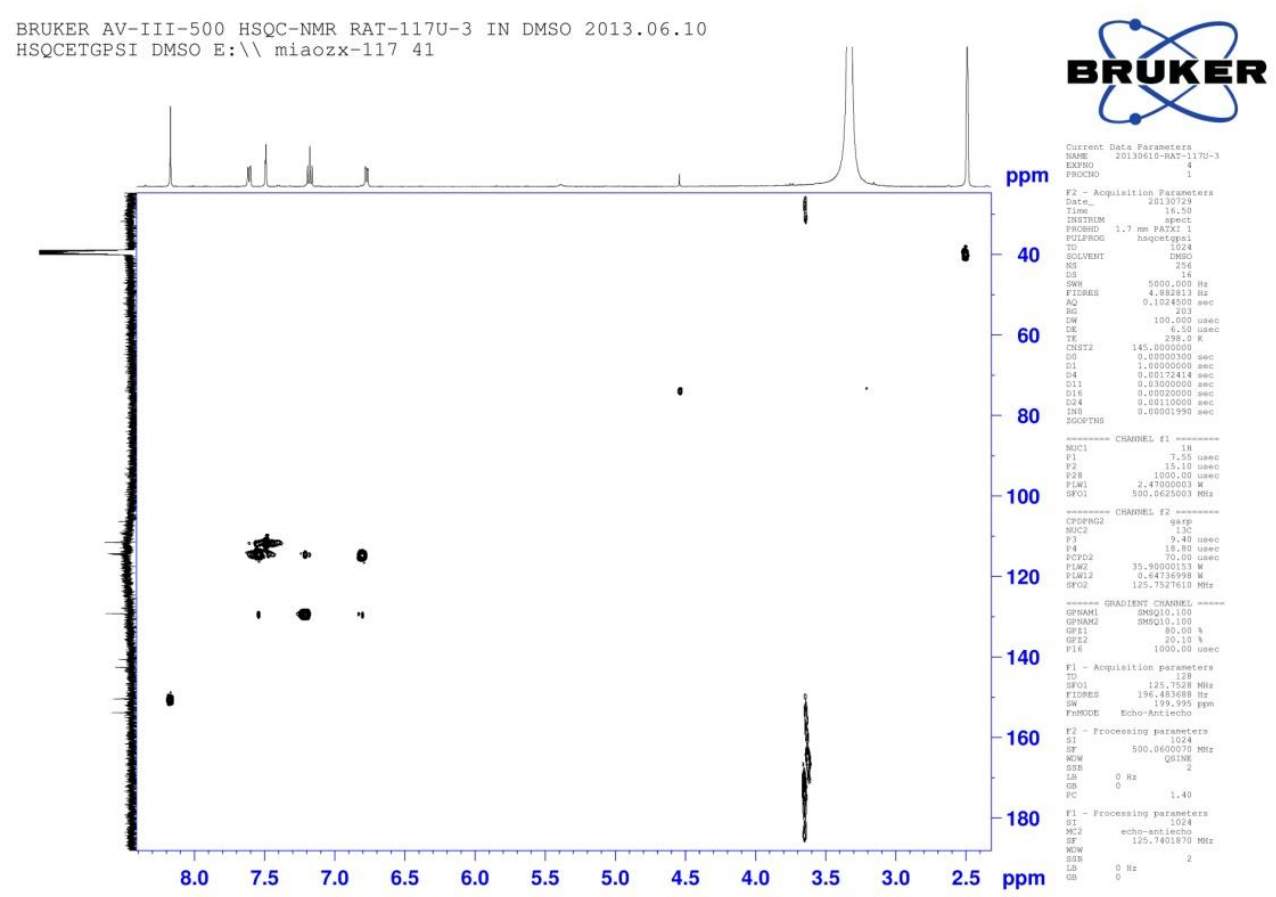

Fig. S3-6 HSQC NMR spectrum of M3 (500 MHz, DMSO, 25 ${ }^{\circ} \mathrm{C}$ ).

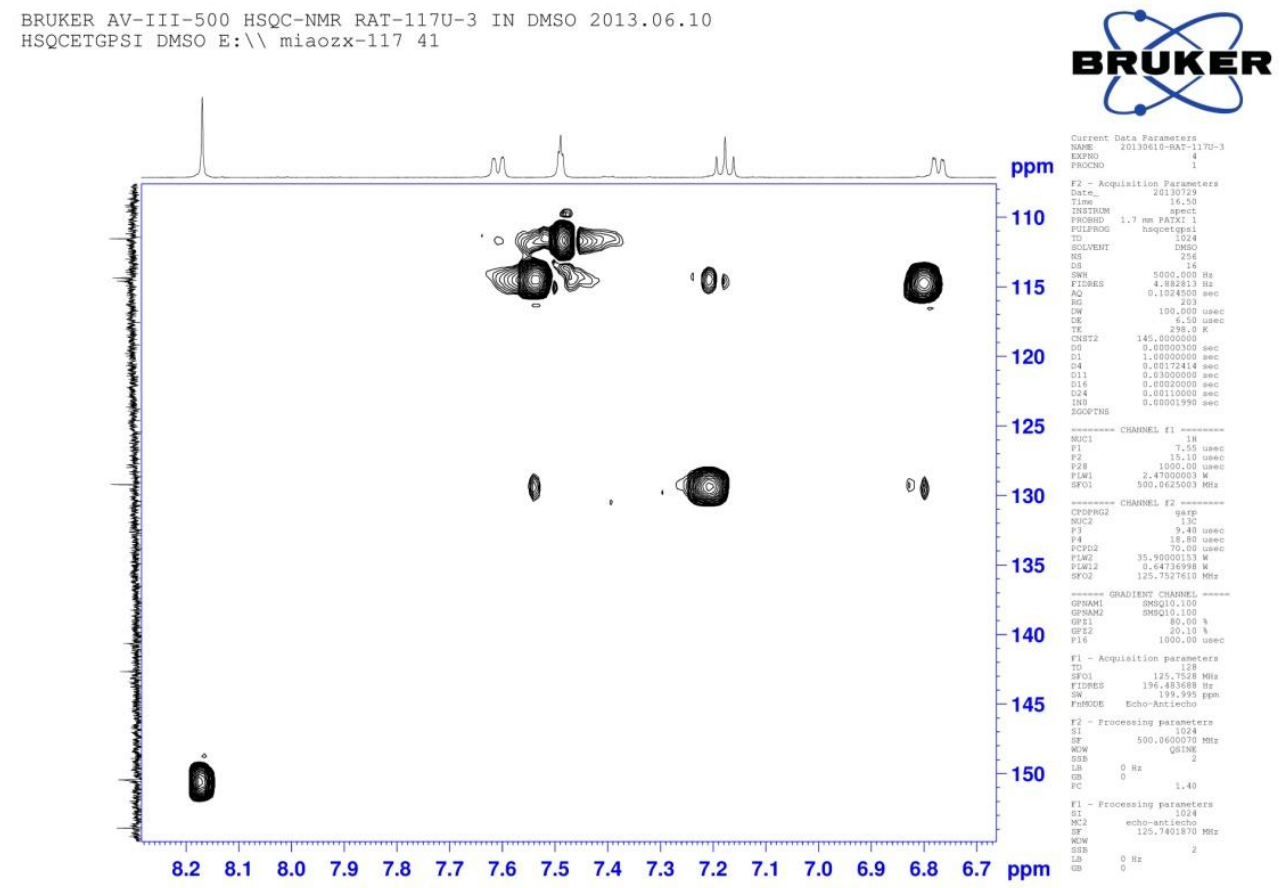


Fig. S3-7 HMBC NMR spectrum of M3 (500 MHz, DMSO, 25 ${ }^{\circ} \mathrm{C}$ ).

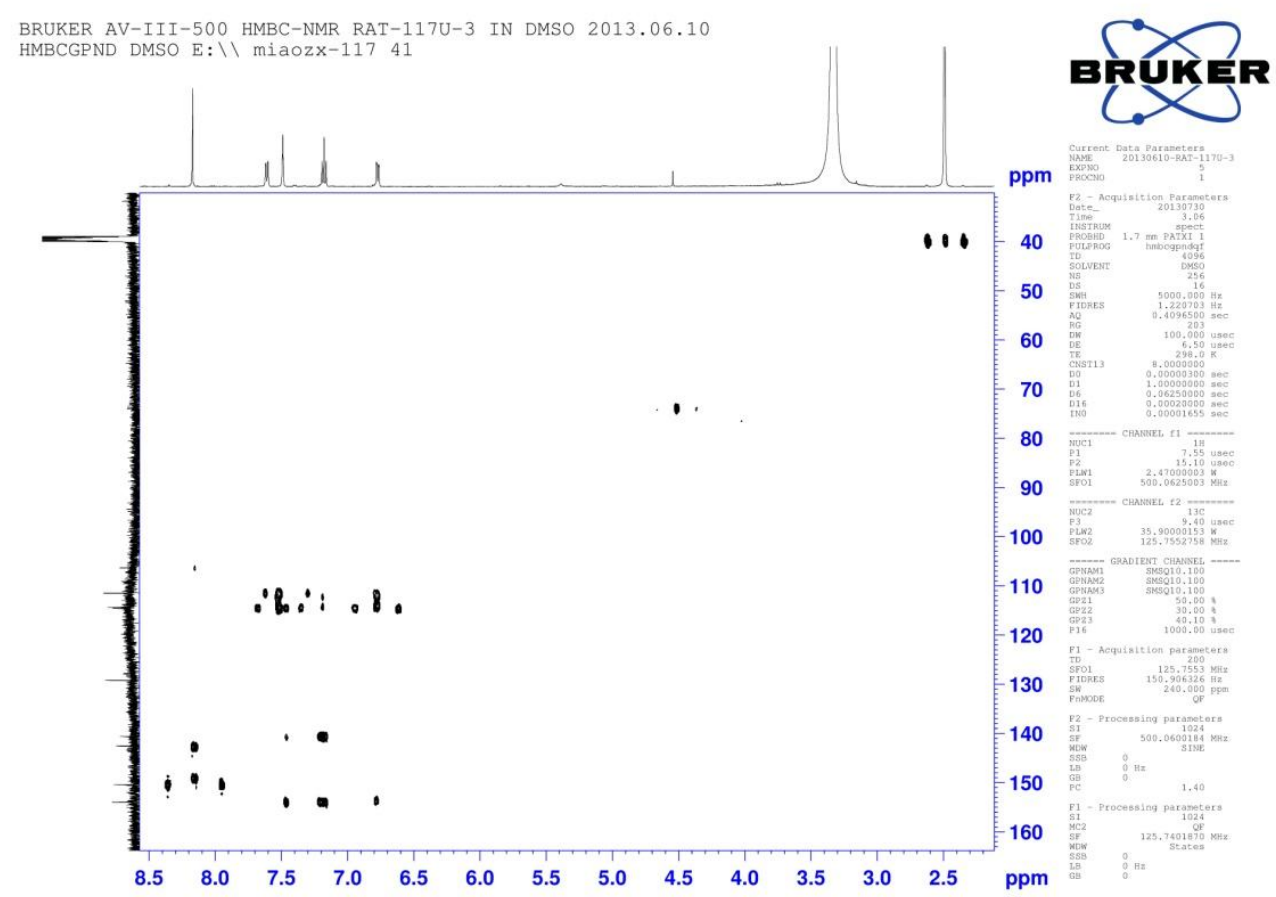

Fig. S3-8 HMBC NMR spectrum of M3 (500 MHz, DMSO, $\left.25^{\circ} \mathrm{C}\right)$.

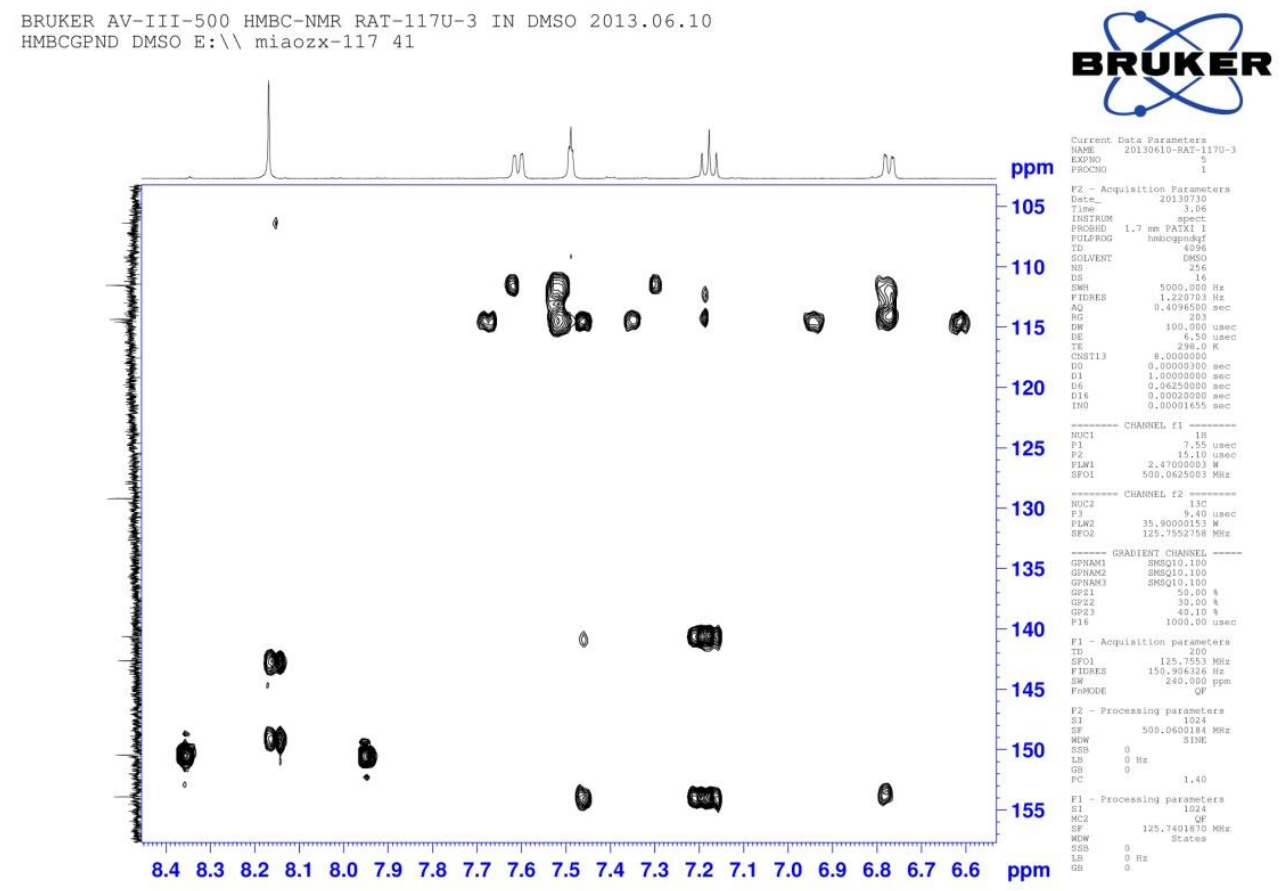

